\title{
Crianças e adolescentes trabalhadores: um compromisso para a saúde coletiva
}

\author{
Child and adolescent workers: \\ a commitment for collective health
}

Carlos Minayo-Gomez 1

Zilah Vieira Meirelles 2

\footnotetext{
1 Centro de Estudos da Saúde do Trabalhador e Ecologia Humana, Escola Nacional de Saúde Pública, Fundação Oswaldo Cruz. Rua Leopoldo Bulhões 1480 , Rio de Janeiro, $R J$ 21040-210, Brasil. 2 Programa de Saúde do Adolescente Trabalhador, Núcleo de Estudo em Saúde do Adolescente, Universidade do Estado do Rio de Janeiro. Rua São Francisco Xavier 524, Rio de Janeiro, $R J$ 20550-011, Brasil.
}

\begin{abstract}
This paper presents some issues pertaining to child and adolescent labor and their impact on health, pointing out the main structural characteristics which are responsible for and socially justify the early incorporation of this segment into the labor market. In Brazil, legislation governing adolescent labor is frequently ignored, showing the need to implement health surveillance programs involving both public institutions and civil rights movements.
\end{abstract}

Key words Work; Child Health; Adolescent Health; Worker's Health

Resumo Neste estudo, apresentam-se sucintamente algumas questões referentes ao trabalho infanto-juvenil e suas repercussões na saúde. Apontam-se as principais características estruturais que circunstanciam e justificam socialmente a incorporação precoce desse significativo e crescente segmento da população no mercado de trabalho. Constata-se que, no Brasil, a legislação existente, que proíbe o trabalho de crianças e normatiza o do menor de 18 anos, freqüentemente não é observada. Diante desse quadro, coloca-se como imperativo desenvolver programas de vigilância à saúde desses trabalhadores, em articulação com órgãos públicos e instâncias da sociedade civil.

Palavras-chave Trabalho; Saúde Infantil; Saúde do Adolescente; Saúde do Trabalhador 


\section{Introdução}

É cada vez mais presente no Brasil a consciência a respeito das expressões de violência contra crianças e adolescentes. São situações variadas de violência, hoje denunciadas por movimentos sociais e políticos, as quais incluem a ação de grupos de extermínio, o tráfico de droga, os abusos e maus tratos, o abandono familiar, o exercício da sexualidade como meio de sobrevivência, a desnutrição, a miséria, entre outros. Dentro desse conjunto de situações desfavoráveis persistentes, destacamos uma das formas de violência mais antiga e presente na sociedade capitalista, a exploração do trabalho infanto-juvenil.

Segundo Thompson (1987), o capitalismo não inventou o trabalho infantil, mas criou as condições para que as crianças não só fossem transformadas em adultos precoces, em trabalhadores 'livres', como destituídas de uma tradição em que trabalho e relações familiares, como eram vividas nas indústrias e domicílios, permitiam a sua reprodução enquanto criança. Ao entrarem no espaço fabril, jogadas às máquinas, permaneciam sob a supervisão de estranhos, forçadas a submeterem-se a longas jornadas de trabalho sem intervalo, recebendo um pagamento inferior ao do adulto pelo seu trabalho.

As justificativas ideológicas apresentadas por setores interessados na utilização dessa força de trabalho têm sido, através da história, a repetição de uma monotonia exemplar. Ela se perpetua desde os momentos de implantação do capitalismo, quando o trabalho infantil foi utilizado em larga escala, e em outros contextos históricos, inclusive os mais recentes, em que tal força de trabalho não apresenta a mesma importância relativa para a indústria. A concepção, no início da industrialização, era de que crianças e adolescentes pobres deveriam trabalhar, porque o trabalho protege do crime e da marginalidade, uma vez que o espaço fabril era concebido em oposição ao espaço da rua, considerado desorganizado e desregulado. Além disso, o trabalho dos menores permitia um aumento da renda familiar, ao mesmo tempo em que podia ser visto como uma escola, a escola do trabalho (Alvim, 1994).

A concepção original do trabalho infantojuvenil ainda se torna bastante atual nos países em desenvolvimento, como também em países centrais do capitalismo. Da mesma forma, não está confinado aos setores tradicionais e não competitivos da economia. A incidência de acidentes de trabalho com crianças e adolescentes é motivo de preocupação, crescendo em se- tores que empregam grande quantidade de mão-de-obra em relação ao capital investido, incluindo indústrias modernas, principalmente aquelas que são estimuladas pela terceirização.

Dados da Organização Internacional do Trabalho (OIT, 1996a) indicam que o trabalho infantil está aumentando na África, na América Latina e, em menor ritmo, na Europa Central, na Oriental e nos Estados Unidos. Contudo, em Portugal, o trabalho infantil se desenvolveu, particularmente nos últimos anos, com a aplicação das normas da União Européia e com os cortes no orçamento da educação, que acentuaram a evasão escolar e a ida de crianças para a economia informal. Calcula-se que hoje, em uma população de nove milhões, duzentas mil crianças trabalhem. Embora não haja dados oficiais, existe, sobretudo, trabalho infantil domiciliar nos ramos têxtil e de couro. Na Alemanha, cerca de seiscentas mil crianças trabalham, e recentemente cerca de 3,8 mil empregos de adultos foram substituídos por postos infantis, desmantelando-se, na prática, instituições e leis que protegem as crianças. Na Espanha, em 1990, o trabalho infantil se restringia às pequenas explorações agrícolas familiares. Hoje calcula-se que quinhentas mil crianças e adolescentes trabalham em diferentes setores da indústria. Esta situação se agravou em 1994, quando houve a reforma do código de trabalho que instituiu a livre demissão. Adultos foram demitidos em massa e substituídos por adolescentes, sem nenhum encargo social para as empresas (Mateos, 1996).

No Brasil, as mudanças que vêm ocorrendo na organização do trabalho desde os anos 70, entre elas a terceirização, têm provocado repercussões nas condições de vida e trabalho nos diferentes grupos da sociedade. Entre elas, destaca-se a situação do trabalho infanto-juvenil, que tem assumido proporções dramáticas e preocupantes, levando um grande contigente de menores a situações extremas de trabalho, as quais, além de interferir no seu processo de crescimento e desenvolvimento, colocam-nos vulneráveis à aquisição de doenças e, até mesmo, de seqüelas que acabam sendo irreversíveis para a sua vida adulta. Configura-se, desta forma, um quadro de graves riscos, que interferem na saúde desta população, especialmente nas diversas formas da economia informal.

Segundo a Organização Internacional do Trabalho (OIT, 1996a), calcula-se que atualmente duzentos milhões de crianças e adolescentes trabalhem em todo o mundo. Para o Instituto Brasileiro de Geografia e Estatística, este número atingia, em 1990, 7,5 milhões de 
brasileiros entre 10 e 17 anos. Representam $11,6 \%$ da força de trabalho do País, e 3,5 milhões deles têm menos de 14 anos. Trata-se de uma mão-de-obra desorganizada, dócil e barata. Em $70 \%$ dos casos, recebem, em média, meio salário-mínimo e, em muitos casos, cumprem jornadas de até 12 horas diárias de trabalho, principalmente os que atuam em ambientes altamente insalubres, como carvoarias, fábricas de sapato, canaviais e outras plantações (Mateos, 1996).

Estes dados indicam a utilização indevida do trabalho de crianças e adolescentes como componente estrutural da economia brasileira. Entretanto, pouquíssimo é feito em nível governamental e sindical para assegurar uma qualidade de ambiente profissional e uma fiscalização dos trabalhos impróprios para esta faixa etária, que são livremente exercidos por jovens e propostos intencionalmente por empregadores.

Ultimamente, este assunto ganhou a mídia e tem sido amplamente discutido por diversos segmentos da sociedade civil. Todavia, tornase importante compreender as causas de seu curso e seus efeitos, que se apresentam carregados de preconceitos e significações sociais, camuflando, muitas vezes, os efeitos devastadores que o trabalho precoce traz para a saúde desta população.

\section{Repercussões sociais do trabalho infanto-juvenil}

Os limites etários que definem a infância e a adolescência apresentam um caráter históricosocial, pois mudam temporalmente e de sociedade para sociedade. Conseqüentemente, os próprios conteúdos dessas categorias sociais, ou seja, os papéis desempenhados e socialmente aceitos para a infância e adolescência têm sido distintos em tempos e em sociedades diferentes (Cervini \& Burger, 1996). No Brasil, o Estatuto da Criança e do Adolescente, instrumento legal vigente, define como criança "a pessoa até doze anos de idade incompletos, e adolescente entre doze e dezoito anos de idade".

Numa definição sociológica, adolescência é uma etapa do desenvolvimento humano que se inicia na infância e que ritualiza a entrada da vida adulta, caracteriza-se por profundas transformações físicas, emocionais e cognitivas. É um período complexo da existência humana no qual se apresentam uma série de questões, que devem ser satisfatoriamente conduzidas, para se alcançar uma vida adulta saudável.
A adolescência não é um período de transição, é parte de um processo de amadurecimento e de intenso aprendizado de vida. A tendência de se limitar o adolescente a "um indivíduo em período de transição" tem favorecido o esquecimento de suas necessidades e a falta de respeito de seus direitos enquanto cidadão. Para que seja possível um outro enfoque sobre o adolescente é preciso que a sociedade valorize o seu potencial de contribuição e o apóie, permitindo que seus pensamentos, desejos, idéias e críticas sejam ouvidas e torne a sua participação eficaz (Ruzany, 1996).

Assim, as necessidades de saúde do adolescente não podem ser encaradas de forma isolada, porque estão intrinsicamente relacionadas com o contexto onde ele está inserido. O conjunto dessas relações vai delineando para o indivíduo uma identidade familiar, sexual e laboral, que lhe permite exercer um papel dentro da sociedade. Esta identidade é a imagem que o sujeito tem dele mesmo e dos vários papéis sociais que venha desempenhar. Não vem pronta, é uma construção vivenciada e potencializada com o conjunto de condições de vida, sociais. Em circunstâncias desfavoráveis, o seu desenvolvimento biopsicossocial fica comprometido, seu desempenho tende a ser difícil e penoso.

Por estas razões, crianças e adolescentes deveriam estar fora do mercado de trabalho, mas, o que ocorre é justamente o oposto. Alguns autores, ao analisar a questão do trabalho infanto-juvenil, procuram colocar em evidência dois fatores fundamentais: o primeiro é a pobreza, que obriga as famílias a adotarem formas de comportamento que incluem a oferta de mão-de-obra dos filhos menores de idade. Conseqüentemente, o grande número de crianças e adolescentes no mercado formal e informal reflete o empobrecimento do País, já que, quanto maior o desemprego, maior o número de trabalhadores adultos e adolescentes ocupados em subempregos, para poderem, juntos, formar uma renda que permita a subsistência da família. Portanto, a pobreza aparece como principal elemento explicativo para o trabalho precoce de criança e adolescente, na medida em que a saída de crianças e adolescentes rumo ao mercado de trabalho é produto de uma decisão familiar, na qual os adultos têm um peso maior. As distintas formas pelas quais as famílias, principalmente as mais pobres, enfrentam as condições objetivas de existência, definindo "quem entra e quando participa das atividades de produção de valores de uso e de produção de mercado", estão ligadas à posição que estas ocupam na estrutura social e às suas 
condições de acesso aos serviços públicos. $\mathrm{O}$ segundo fator explicativo é a estrutura de mercado de trabalho, que oferece espaços apropriados à incorporação desse contigente específico de mão-de-obra (Cervini \& Burger, 1996).

Assim, as decisões das famílias decorrem principalmente do efeito combinado entre pobreza e mercado de trabalho. Neste sentido, o entendimento do trabalho do adolescente está longe de corresponder apenas a um indicador de participação social, pois o seu ingresso e a sua permanência no mercado de trabalho pode estar significando, em muitos casos, um sinal de pauperização. Além de ser fruto do aviltamento dos níveis salariais, constitui um fator de realimentação deste processo, por representar mão-de-obra mais barata, contribuindo para o rebaixamento da remuneração média do conjunto de trabalhadores.

Inscrevendo-se, predominantemente, numa estratégia de sobrevivência econômica das famílias mais pobres, o trabalho de crianças e adolescentes acaba por lhes impor um custo social elevado: a renúncia a um grau de escolarização maior, capaz de lhes garantir, no futuro, melhor colocação no mercado de trabalho, ou uma sobrecarga de tarefas da qual resulta considerável desgaste físico e mental, pois a atividade laborativa é uma fonte de estresse emocional de origem social na infância e adolescência. Além disso, tal atividade diminui o tempo disponível da criança para seu lazer, vida em família, educação, e oportunidade de estabelecer relações de convivência com seus pares e outras pessoas da comunidade em geral. Por outro lado, o adolescente está em desvantagem nas relações de força no trabalho, quando sujeito a inadequadas condições e a regras disciplinares próprias do processo produtivo.

Nesta perspectiva de análise, não podemos deixar de situar alguns elementos que configuram o significado social do trabalho de crianças e adolescentes. Existe bastante consenso, na sociedade, em relação ao fato de que a criança não deve exercer nenhuma atividade laborativa, devido a sua imaturidade biológica e emocional. Verifica-se uma maior preocupação social em garantir espaços de lazer, educação e saúde para que os mais jovens possam desenvolver atividades de socialização.

Historicamente, o adolescente de classe menos favorecida sempre esteve presente na produção econômica. O olhar da sociedade sobre este fato acaba reforçando esta imagem distorcida, na medida em que concebe o trabalho como importante para o adolescente "aprender como é a vida", "levar a vida a sério".
Essas concepções se apresentam hoje através de expressões como "ocupar o seu tempo", "tirá-lo da rua”, "tirá-lo da marginalidade”, "aprender uma profissão”, "ajudar a família”. Tais representações se manifestam em condutas e chegam a ser institucionalizadas, através da criação de programas educativos, sob a justificativa de promover políticas sociais redistributivas, que tendem a atuar numa perspectiva meramente profissionalizante, constituindo-se em instrumentos de legitimação para a manutenção e reprodução social da pobreza e da estrutura ocupacional.

A partir dos anos 90, esses programas tiveram um maior impulso, agindo como alternativas educacionais para crianças e adolescentes que elegem a rua como espaço de sobrevivência e de resistência social. Entretanto, ao invés de essas ações contribuírem para o fomento da cidadania, acabam reforçando toda uma situação de exclusão social, visto que não apresentam uma proposta pedagógica mais ampla que incorpore questões próprias do adolescente, nas áreas de saúde, educação, cultura, lazer, trabalho, entre outros.

\section{Impacto do trabalho na saúde de crianças e adolescentes}

Um grande contingente de crianças e adolescentes trabalham hoje no Brasil em condições abusivas de exploração e de perigo. Suas atividades laborativas são exercidas em diversos setores. Na agricultura (plantações de cana-deaçúcar, laranja etc), desempenhando trabalhos pesados e expostos a muitos riscos, associados à introdução de máquinas modernas e produtos químicos. Na indústria, em ocupações perigosas (fabricação de vidros, calçados, construções, tecelagem etc). Nas ruas, como catadores de lixo, vendedores ambulantes e prostitutas, sob ameaça de violência das gangs e da polícia. Em total escravidão ou em combinações e arranjos de trabalho que se aproximam dessa condição. Em casa, cuidando de crianças mais novas ou ajudando nas fazendas e negócios da família, durante tantas horas, que impossibilitam o divertimento e a dedicação à escola (OIT, 1996b).

A fim de ilustrar, foram selecionadas algumas das atividades exercidas por crianças e adolescentes, em diversos estados brasileiros, e seus efeitos nocivos sobre esta população (Tabela 1).

No caso do trabalho infantil, o conceito de trabalho de risco deve estar centrado na criança, focalizando não somente fatores de risco 
Agravos à saúde em atividades exercidas por crianças e adolescentes em alguns estados.

\begin{tabular}{|c|c|c|}
\hline Atividades & Estados & Agravos \\
\hline $\begin{array}{l}\text { Cultura e colheita de frutas, cereais, } \\
\text { cana-de-açúcar, café, cacau, algodão } \\
\text { e outras. }\end{array}$ & $\begin{array}{l}\text { SE, PE, RO, PA, AL, BA, PI, MA, } \\
R N, C E, G O, M T, M S, S P, R J, M G, S C\end{array}$ & $\begin{array}{l}\text { Intoxicação por agrotóxicos, problemas de coluna, } \\
\text { LER, picadas de insetos e mordidas de animais } \\
\text { peçonhentos, lesões por instrumentos cortantes. }\end{array}$ \\
\hline Cerâmica e olaria. & $\begin{array}{l}C E, P B, R N, B A, P E, P I, S E, M A, R S, S C, P R \\
A M, P R, R O, A L, P B, G O, M T, E S, R J, S P, M G\end{array}$ & $\begin{array}{l}\text { Dermatoses, cortes por maquinário, queimaduras, } \\
\text { mutilações, LER, lesões pulmonares e auditivas, } \\
\text { lombalgias e fadiga muscular. }\end{array}$ \\
\hline Pedreiras & $\begin{array}{l}C E, A L, B A, R N, P B, P I, P E \\
G O, S C, P R, M G, R J, S P, E S\end{array}$ & $\begin{array}{l}\text { Cortes, perdas auditivas e visuais, fadiga muscular, } \\
\text { lombalgias, LER e pneumoconioses. }\end{array}$ \\
\hline Carvoaria & $\mathrm{MT}, \mathrm{GO}, \mathrm{MG}, \mathrm{MS}, \mathrm{PA}, \mathrm{AM}$ & $\begin{array}{l}\text { Problemas respiratórios, queimaduras, mutilação } \\
\text { por motosserra, dermatoses. }\end{array}$ \\
\hline Serraria / Madeireira & $\mathrm{MT}, \mathrm{MS}, \mathrm{RS}, \mathrm{PR}, \mathrm{SC}$ & $\begin{array}{l}\text { Cortes, mutilações, acidentes fatais, lesões } \\
\text { musculares e auditivas, dermatoses. }\end{array}$ \\
\hline Cultura do sisal & BA & $\begin{array}{l}\text { Cortes e mutilações, problemas respiratórios } \\
\text { e auditivos, tenossinovite. }\end{array}$ \\
\hline Extração de sal & CE, PI, RN & Queimaduras, problemas de coluna e LER. \\
\hline Tecelagem & $\mathrm{RN}, \mathrm{PB}, \mathrm{CE}$ & LER e contaminações por poeira, cloro e tintas. \\
\hline Seringais & MT & $\begin{array}{l}\text { Contaminação por agrotóxicos, doenças } \\
\text { respiratórias, malária e dengue. }\end{array}$ \\
\hline $\begin{array}{l}\text { Programas de inserção } \\
\text { no mercado de trabalho. }\end{array}$ & $P R, M T, M S, R O, P B, M A$ & $\begin{array}{l}\text { Atropelamentos, lesões físicas, alterações do sono, } \\
\text { distúrbios psicoemocionais e LER. }\end{array}$ \\
\hline $\begin{array}{l}\text { Trabalhos na rua: catador de lixo, } \\
\text { engraxates, ambulantes, entregadores } \\
\text { de jornal, serviços de panfletagem. }\end{array}$ & $M T, D F, M S, R J, S P, A L, C E, P E, P I, S E, G O$ & $\begin{array}{l}\text { Intoxicação por alimentos deteriorados e substâncias } \\
\text { químicas, verminoses, diversas formas de violência, } \\
\text { problemas de coluna, LER, alterações do ciclo } \\
\text { biológico, acidentes de trânsito. }\end{array}$ \\
\hline
\end{tabular}

Fonte: MT, 1996.

externos e imediatos, mas, também, aqueles que ameaçam seus crescimento e desenvolvimento ao longo do tempo. Estas dimensões podem ser agrupadas dentro de duas categorias: a física e a psicossocial. Ambas são cruciais para o futuro da criança, afetam-se mutuamente e as ameaças em cada uma delas devem ser consideradas, em grau de importância.

Situações de trabalho impróprias à saúde e ao desenvolvimento físico da criança normal podem causar efeito imediato, a médio ou a longo prazo. Acarretam perda de visão e audição, mutilação de membros, desvios na estrutura corporal, atrofia do crescimento. Alguns destes sintomas podem levar anos para aparecer (Asmus et al., 1996).

Uma das conseqüências mais sérias e comuns do trabalho infantil, pelo tempo que absorve e pela exaustão que provoca, é impedir o desenvolvimento intelectual da criança.
Para o adolescente, a atividade laborativa transforma-se freqüentemente em fonte de estresse, ao contrapor-se a seu processo dinâmico e complexo de diferenciação e maturação. Ele precisa de tempo, espaço e condições favoráveis para realizar sua transição em direção à vida adulta; uma transição marcada por intensas contradições, quando o adolescente vive momentos de alta ansiedade e de solidão pelas ardentes ou estéreis preocupações filosóficas e pelo desejo de liberdade diante de sentimentos de opressão, principalmente no que diz respeito a normas e disciplinas. Assim, o trabalho acaba impondo a esses jovens um conjunto de situações desfavoráveis, contrapondo-se ao seu momento de descoberta individual, e rotinas e tarefas lhes são designadas de forma mais dura que aos próprios adultos.

Em suma, o trabalho, quando não oferecido adequadamente para esta população, passa 
a representar um ritual de violência à saúde, capaz de gerar graves seqüelas para a vida adulta. A falta de alternativas, somada a ausência de proteção, permitida por lei, colocam crianças e adolescentes num status inferior ao do conjunto dos trabalhadores. Nas piores condições, elas podem estar sujeitas a intimidações e abusos físicos, contra os quais não podem se defender e tem poucos recursos para obter compensações nas ocorrências de danos ou injustiças.

No Brasil, a Consolidação das Leis do Trabalho - CLT, em 1952, dedica um capitulo à regulação do ingresso no mercado de trabalho dos adolescentes entre 14 e 18 anos, sendo parcialmente ratificada, em 1990, no Estatuto da Criança e do Adolescente, que abre o precedente para o trabalho na forma de bolsaaprendizagem para aqueles com menos de 14 anos. Para os menores de 18 anos, a CLT proíbe o trabalho noturno, bem como em atividades e locais perigosos ou insalubres. Além disso, condiciona o exercício da atividade laborativa à permanência na escola e delega à autoridade competente e/ou ao responsável legal do menor o direito de retirá-lo do local de trabalho, caso sejam verificadas condições prejudiciais ao seu desenvolvimento físico e psíquico.

Apesar da legislação existente que protege esse trabalhador - freqüentemente não cumprida -, esta população permanece sujeita a condições potencialmente lesivas a sua saúde. Torna-se necessário, portanto, uma política intersetorial envolvendo os órgãos públicos (Ministérios do Trabalho, da Justiça, da Saúde e da Educação), os sindicatos, as ONGs e, principalmente, as instâncias de proteção e defesa dos direitos da infância e adolescência (Conselhos Municipais da Criança e do Adolescente e Conselhos Tutelares). Essa atuação conjunta possibilitaria, dentre outras ações, o desenvolvimento de um programa eficaz de vigilância à saúde desses trabalhadores, visando à erradicação do trabalho infantil e à fiscalização da exploração do trabalho juvenil.

Finalmente cabe registrar a necessidade de maior investimento em estudos e pesquisas capazes de desvendar os efeitos que o trabalho causa a essa população e fornecer subsídios para repensar ou criar estratégias viáveis de intervenção.

\section{Referências}

ALVIM, R., 1994. O Trabalho Infanto-Juvenil em Discussão. Terceirização: Diversidade e Negociação no Mundo do Trabalho. São Paulo: Hucitec.

ASMUS, C. I. F.; BARKER, S. L.; RUZANY, M. H. \& MEIRELLES, V. Z., 1996. Riscos ocupacionais na infância e na adolescência: uma revisão. Jornal de Pediatria, 72:203-208.

CERVINI, R. \& BURGER, F., 1996. O Menino Trabalhador no Brasil Urbano dos Anos 80. São Paulo: Cortez.

RUZANY, M. H., 1996. Saúde do Adolescente: um Desafio Ético. Rio de Janeiro: Uerj. (mimeo.)

OIT (Organização Internacional do Trabalho), 1996a. Trabajo Infantil: Que Hacer? Genebra: OIT.

OIT (Organização Internacional do Trabalho), 1996b. Programa Internacional para a Eliminação do Trabalho Infantil. São Paulo. (mimeo.)

MATEOS, S. B., 1996. Quem explora a mão-de-obra infantil. Revista Atenção, 2:9-16.

MT (Ministério do Trabalho), 1996. Diagnóstico Preliminar dos Focos de Trabalho da Criança e do Adolescente no Brasil. Brasília: MT.

THOMPSON, E. P., 1987. A Formação da Classe Operária Inglesa. Rio de Janeiro: Paz e Terra. 